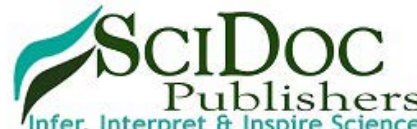

International Journal of Dentistry and Oral Science (IJDOS) ISSN: 2377-8075

\title{
Prevalence And Severity Of Dental Caries And Oral Hygiene Status Among The 35-40 Years Old Adult Population Attending A Private Dental College- A Hospital Based Cross Sectional Study
}

Research Article

Anupama Deepak ${ }^{1}$, Jayashri Prabakar² ${ }^{*}$ M. Jeevitha ${ }^{3}$

${ }^{1}$ Saveetha Dental College and Hospitals, Saveetha Institute of Medical and Technical Sciences, Saveetha University, Chennai, India.

${ }^{2}$ Senior Lecturer, Department Of Public Health Dentistry, Saveetha Dental College and Hospitals, Saveetha Institute of Medical and Technical Sciences, Saveetha University, Chennai, 600077, India.

${ }^{3}$ Senior Lecturer, Department of Periodontics, Saveetha Dental College and Hospitals, Saveetha Institute of Medical and Technical Sciences, Saveetha University, Chennai, 600077, India.

\section{Abstract}

\begin{abstract}
Dental caries is one of the most infectious diseases worldwide. Dental caries also referred to as tooth decay is a multifactorial disease characterized by demineralisation of inorganic substance of the tooth. Progression of dental caries was directly proportional to the poor oral health maintenance. Poor oral health affects the individuals identity resulting in low confidence levels. Among the older age individuals, dental caries were more common, due to poor oral maintenance and dental neglect. Dental neglect is the main reason for caries at an older age, due to poor socioeconomic status, lifestyle etc. The main aim of this study was to assess the prevalence and severity of dental caries and oral hygiene status among the 35-40 years adult population attending a private dental college. This was a record based study with a sample size of 701 , irrespective of the gender. This study was conducted in a university setting in Saveetha Dental College, Chennai. Data was collected from a case sheet record. The data was then categorised according to their age groups, gender, DMFT index values and OHIS index values. The coding was done in MS Excel Sheets. Results were then carried out using IBM SPSS Version 20.0 followed by the tabulation and graphical illustration. Independent t-test was used to compare the mean DMFT and OHI score with age and gender respectively. The results revealed that females $(7.80 \pm 3.88)$ were more prone for caries than the males $(6.53 \pm 3.46)$ with high prevalence was found among the $38-40$ years age group. In conclusion, dental caries were highly prevalent among females with a mean value of 7.8 and commonly among the age group 38-40 years.
\end{abstract}

Keywords: Dental Caries; DMFT Index; OHIS Index; Oral Hygiene.

\section{Introduction}

Dental caries, also referred to as tooth decay or cavities, are one of the most common and widespread diseases today. Dental caries is a multifactorial infections disease characterised by demineralisation of inorganic substances. Poor oral health can lead to the formation of dental caries [1]. Prevalence of dental caries is generally associated with poor oral maintenance affecting the quality of life [2]. Dental caries incidence is commonly seen around the middle age group having 3 peaks: coronal decay of primary and permanent dentition and root decay [3]. WHO studies have shown the epidemiological significance and the severity of dental caries in oral health [4]. It is believed that this disease has high prevalence worldwide. During the years, there is an increase in reports of dental caries, resulting in the emerging public health issues that are related to the prevalence in the dental caries [5]. It is found to be common among the low socioeconomic groups, children and new immigrants [6].

Dental caries are more common in children than in the adults in the form of early childhood caries, probably due to the improper bottle feeding and poor oral hygiene. Preventive measures for this are the pit and fissure sealants used in both children and adults wherein they form resin tags [7-9]. Dental neglect is one of the

\section{*Corresponding Author}

Jayashri Prabakar,

Senior Lecturer, Department Of Public Health Dentistry, Saveetha Dental College and Hospitals, Saveetha Institute of Medical and Technical Sciences, Saveetha University, Chennai, 600077 , India.

Tel: +919841788803

E-mail: jayashri.sdc@saveetha.com

Received: November 10, 2020

Accepted: December 15, 2020

Published: December 18, 2020

Citation: Anupama Deepak, Jayashri Prabakar, M. Jeevitha. Prevalence And Severity Of Dental Caries And Oral Hygiene Status Among The 35-40 Years Old Adult Population Attending A Private Dental College- A Hospital Based Cross Sectional Study. Int J Dentistry Oral Sci. 2020;7(12):1247-1251. doi: http://dx.doi.org/10.19070/2377-8075-20000246

Copyright: Jayashri Prabakar 2020 . This is an open-access article distributed under the terms of the Creative Commons Attribution License, which permits unrestricted use, distribution and reproduction in any medium, provided the original author and source are credited. 
main reasons for progression of the disease in both adults and children. Early loss of the teeth can result in various complications like supraeruption, space loss etc, and these are more prevalent in children as the primary teeth form a guide for eruption of the permanent teeth [10]. Decayed teeth in children can be prevented by stainless steel crowns and endodontic procedures thereby arresting caries progression, but bacterial accumulation is seen around the crown margins in individuals with poor oral hygiene [11].

The relationship between oral health and behaviour is complex as poor oral health implications on poor behaviour [12]. Individuals who have knowledge on this personal control and oral health have been reported to have better adopted self-care behaviour. There are a number of factors that can lead to poor oral hygiene in adults, habits such as tobacco smoking, chronic alcohol consumption, nutrition deficiency, stress and socioeconomic status [13]. Dietary pattern plays a major role in caries formation. Increase in sugar intake can lead to formation and progression of caries resulting in poor oral hygiene. Frequency of snacking between meals can predispose to caries [14]. Malnutrition and consumption of carbonated drinks can also predispose to caries $[15,16]$.

Dental caries prevalence increases with age [17]. In adults, increase in dental caries is found to be due to lack of dental care and health related issues [18]. WHO have adopted a series of programs on defining caries as a tooth decay extending to the dentin (who,1997). The use of DMFT index for adults can be attributed to loss of teeth due to dental caries or other reasons such as bone loss or mobility. DMFT index is a universally accepted index in evaluating the caries frequency. It includes the decayed, missed, and the filled teeth scores which are graded according to each individual, and the total scores reveal the caries prevalence. The high levels of untreated caries is prevalent among the adults due to limited access, cost and availability [19]. This can be prevented by the use of fluoridated toothpaste, optimal fluoride containing drinking water $[20,21]$. These are more prevalent in rural areas than in the adult population. Studies revealed that among the $\mathrm{D}, \mathrm{M}, \mathrm{F}$ scores, the component $\mathrm{D}$ was highly predominant among the adults, whereas in children, $\mathrm{D}$ and $\mathrm{M}$ scores were predominant [22]. Studies have shown that people with disability have poor oral hygiene [23]. Awareness and training towards various disaster management is essential for all in the health care delivery sector [24].

Oral health therefore has a strong association in individuals well being. Good oral hygiene practices result in regression of the inflammation of periodontium. Plaque and calculus accumulation can lead to dental caries formation and if left untreated can cause a major damage to the tooth and supporting periodontium. Good oral hygiene practices improve oral health [25]. Untreated caries in the oral cavity leads to poor oral health further leading to halitosis and infections [26]. Therefore, the aim of this study was to determine the severity of dental caries and the oral hygiene status among the adult population.

\section{Materials And Methods}

\section{Study Design}

This present study was a descriptive, record based study conduct- ed in a university setting at Saveetha dental college, Chennai . The Case sheets of all the Patients in OP Department of Saveetha dental college and the final sample size of 701 was obtained from the data of 86,000 patients visited Saveetha dental college during the time period of June 2019 to March 2020. The approval was given by the institutional ethics committee of SIMATS. This study was reviewed by two reviewers. The total sample size of this study was 701 subjects and the study participants were distributed in the age group between $35-40$ years. The sampling bias was minimised by using a simple random technique of data collection. This retrospective study was approved by the following ethical approval number of the university, SDC/SIHEC/2020/ DIASDATA/0619-0320. The internal validity of the study was the random selection of subjects and were assessed based on universally accepted OHI-S index and DMFT index.

Assessment of dental caries was carried out using decayed, missing, and filled teeth (DMFT) index by Klein, Palmer, Knutson for permanent dentition. The tooth was considered carious (D component) if there was visible evidence of a cavity, including untreated dental caries. The missing ( $\mathrm{M}$ component) included teeth with indications for extractions or teeth extracted due to caries. The filled (F component) included filled teeth.

Assessment of Oral hygiene was carried out using an oral hygiene index simplified (OHI-S) by Greene and Vermillion for permanent dentition. The tooth was scored according to the presence of debris and calculus present and given scoring of 0 , if there were no debris or stains present, 1 if there was soft debris or calculus covering not more than one third of tooth's surface, 2 if there was soft debris or calculus covering more than one third of tooth's surface, 3 if there was soft debris or calculus covering more than two thirds of tooth's surface. The total of these scores was then calculated separately and assigned good (0-1.2), fair (1.3$3)$ and poor (3.1-6).

\section{Data collection/Tabulation}

The data collected was entered in MS Excel Sheets and excel tabulation is done. The data was then imported to SPSS. Graphical and table illustration was done by variable definition process.

\section{Statistical Analysis}

The statistical tests used were the descriptive and inferential statistics. The software used was the IBM SPSS Version 20.0. The dependent variables were the DMFT and OHI-S whereas the independent variables were the age and gender. Descriptive statistics were expressed by means of frequency, percentage, mean and standard deviation. Independent t-test was used to compare the mean DMFT and OHIS score with age and gender respectively. Pearson correlation was used to find the relationship between DMFT and OHIS score.

\section{Results And Discussion}

In the present study, from Figure 1, 48.1\% of subjects belonged to the $35-37$ years age group and $51.9 \%$ of subjects belonged to the $38-40$ years age group. Figure 2, $46.8 \%$ of subjects were females and $53.2 \%$ of subjects were males . From Figure 3, it is observed that among $35-37$ years, the mean is $(6.88 \pm 3.72)$ whereas 
in $38-40$ years, the mean is $(7.35 \pm 3.71)$, with p-value 0.094 . There was no statistically significant difference observed on association between age and mean DMFT score using Independent ttest. From Figure 4, on association between gender with mean DMFT score, females (7.80 \pm 3.88$)$ were more prone for caries than males $(6.53 \pm 3.46)$ and were found to be statistically highly significant. From Figure 5, On association between age and mean OHIS score, it is observed that among 35-40 years the mean is $(1.74 \pm 1.50)$ whereas in $38-40$ years, the mean is $(1.91 \pm 0.87)$ with a p value of 0.977 , statistically insignificant association. From Figure 6, on association between gender with mean OHIS score, females $(1.75 \pm 1.60)$ had relatively poorer oral hygiene status than males $(1.73 \pm 1.07)$ and were found to be having a negligible positive association. From Table 1, On correlation between Dental caries and Oral Hygiene Status, Pearson correlation; $\mathrm{p}$ value= $\mathrm{p}<0.05$; hence, statistically significant, showing a positive significant correlation exists between dental caries and the oral hygiene status.

Figure 1. Bar graph represents the distribution of study subjects based on Age, where X-axis represents age of the subjects and Y-axis represents the percentage distribution. $48.1 \%$ of the study subjects were distributed in the age group between $35-37$ years (Blue) and $51.9 \%$ of the study subjects were in the age group between $38-40$ (Green).

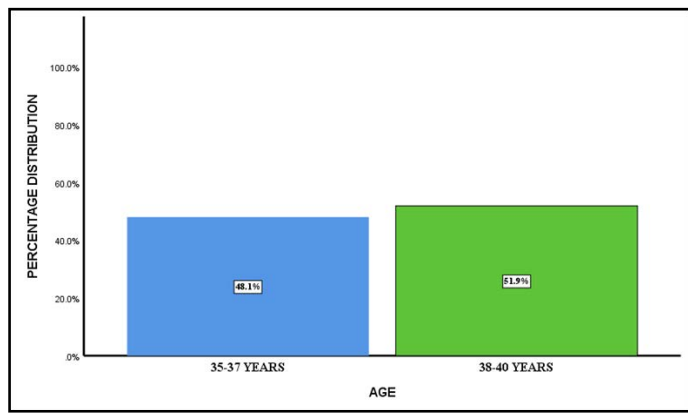

Figure 2. Bar graph represents the study subjects based on Gender, where X-axis represents gender of the subjects and Y-axis represents percentage distribution. $46.8 \%$ of the study population were females (Blue) and $53.2 \%$ were males (Green).

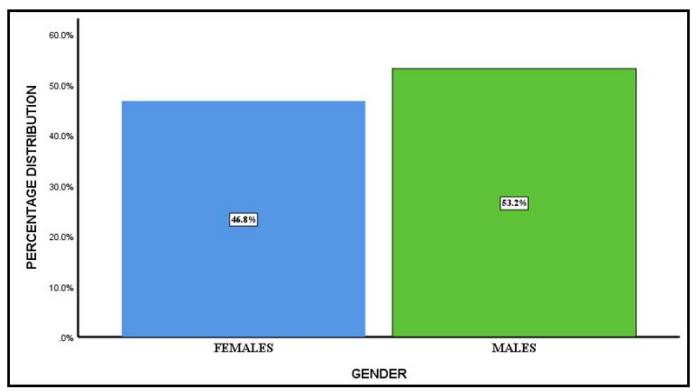

Figure 3. Bar graph represents the association between mean DMFT score and Age of the study subjects. Independent t-test was used to find the difference between subjects of 35-37 years and 38-40 years with respect to mean DMFT score and was found to be statistically not significant ( $\mathrm{t}$ value-1.65 and p value $>0.05$ ). Even though the test was found to be statistically not significant, 38-40 years (Green) had a higher mean DMFT score of $7.35 \pm 3.71$ than $35-37$ years which was found to be $6.88 \pm 3.72$.

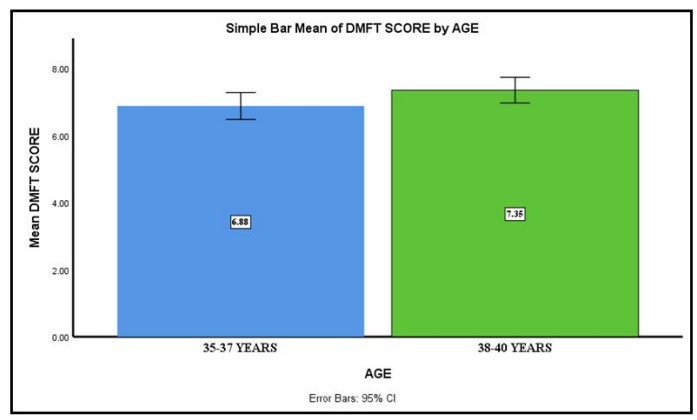

Figure 4. Bar graph represents the association between mean DMFT score and Gender of the study subjects. Independent t-test was used to find the difference between Gender and mean DMFT score and was found to be statistically highly significant (t value- 4.57 and $\mathrm{p}$ value $<0.001)$. This proves that female study participants (Blue) was found to have a higher mean DMFT score of $7.80 \pm 3.88$ than males(Green)which was 6.53 \pm 3.46.

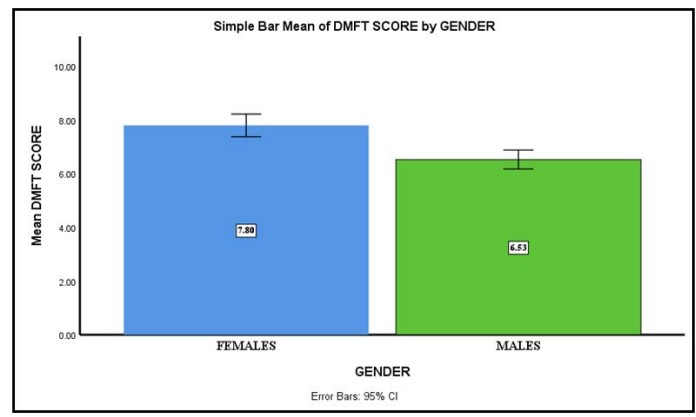


Figure 5. Bar graph represents the association between mean OHIS score and Age of the study subjects. Independent t-test was used to find the difference between subjects of 35-37 years and 38-40 years with respect to mean OHIS score and was found to be statistically not significant ( $t$ value- 1.79 and $p$ value >0.05).Even though the test was found to be statistically not significant, 38-40 years(Green) had a higher mean OHIS score of $1.91 \pm 0.87$ than $35-37$ years which was found to be $1.74 \pm 1.50$ (Blue).

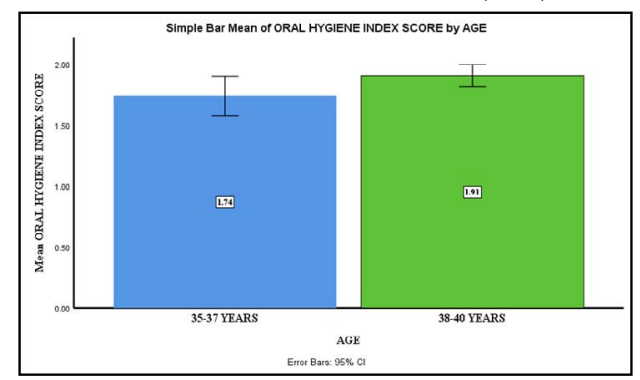

Figure 6. Bar graph represents the association between mean OHIS score and Gender of the study subjects. Independent t-test was used to find the difference between subjects of females and males with respect to mean OHIS score and was found to be statistically not significant ( $t$ value- 0.18 and $p$ value $>0.05$ ). Even though the test was found to be statistically not significant, females (Blue) had a higher mean OHIS score of $1.75 \pm 1.60$ than males (Green) which was $1.73 \pm 1.07$.

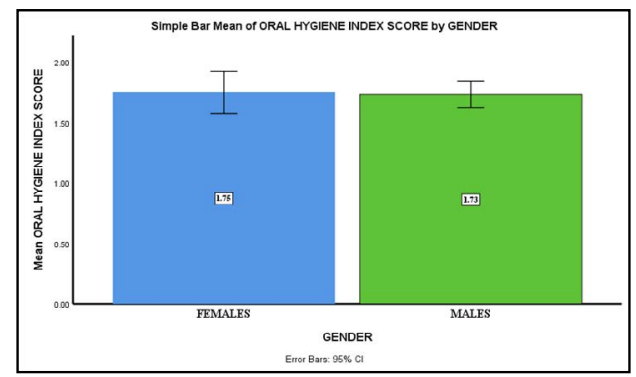

Table 1. Correlation between Dental caries and Oral Hygiene Status. $*$ Pearson correlation; $\mathrm{p}$ value $=\mathrm{p}<0.05 ;$ hence, statistically significant, showing a positive significant correlation exists between dental caries and the oral hygiene status.

\begin{tabular}{|c|c|c|}
\hline Variables & $\begin{array}{c}\text { Pearson's Correlation } \\
\text { Value }\end{array}$ & P Value \\
\hline $\begin{array}{c}\text { Dental caries and Oral } \\
\text { Hygiene Status }\end{array}$ & $0.911^{*}$ & 0.004 \\
\hline
\end{tabular}

Therefore from the above study, caries was a major risk factor. There were few similar studies citing the dental caries and oral hygiene status correlation. Scientific research continues in making progress in identification of best practices for prevention of best practices for prevention of dental caries. One best way is fluoridated toothpaste, they form a protective layer in prevention of caries. A cross sectioned survey conducted in China revealed that dental caries increase with age. Another study revealed that in children dental caries in primary dentition can be cause for caries in permanent dentition [27] whereas in contrary, a study conducted in Nigeria, showed that females have better oral health than males [28]. Regular dental check-up is not a common event in developing countries. Males with oral habits have poor oral health.

Studies showed that $70 \%$ of the individuals rinsed their mouth after every meal. The mean increase in females to dental caries could be due to the improper dental health care. The findings of high DMFT score is comparable with other studies [29]. Our study had less sample size which could be the reason for vary in the results. In our study, the prevalence was more for the $38-40 \mathrm{yrs}$ age-group. These individuals, especially working women and men have stress as their main reason. Low caries risk in individuals can be due to less calories and sugar intake. These studies also revealed that these subjects required only surface fillings [30]. The oral hygiene status of the individual was assessed using the OHI$\mathrm{S}$ which assesses both the soft and hard tissue deposits on the tooth's surface, and is calculated as the sum of Debris \& Calculus
Index, whereas subjects in our study had fair scores. From table I and II, based on the DMFT values, it shows that the decayed (D) component is highly predominant. Poor oral health caused by dental caries can lead to gingival diseases. According to age and OHI-S calculation, the older age was more prevalent. These can also have an effect on systemic diseases like CVS diseases, hypertension etc. Common prevention of dental plaque and calculus can be done by flossing, proper brushing, rinsing mouth after every meal. Frequent dental check up. There are certain natural phytochemicals present in fruits and vegetables that have strong antioxidant and anti-proliferative activities which can help in the reduction of caries [31]. Also, natural products such as green tea, and chlorhexidine and fluoride-containing dentifrices like nova min, bio min and remin pro helps in reducing the accumulation of oral microbial flora $[32,33]$. An awareness on oral health should be developed on cessation of oral habits such as smoking which can be done by nicotine replacement therapy [34]. In demonstrating, the usage of fluoridated toothpaste, oral diseases is preventable whereas oral health is avoidable. Caries is a disease, when diagnosed early can be prevented using management such as nonsurgically like cavity fillings and restoration.

Poor oral health can affect one's personal behaviour, anterior caries can lead to loss of self-confidence and can lead to patients lack of smiling. Genetics can also be a cause for caries progression. Individual health literacy can affect the poor oral health. Improper brushing can lead to an accumulation of calculus of plaque around the tooth and causes biofilm formation, these can contain 
bacteria which are capable of fermenting carbohydrate and decrease in $\mathrm{pH}$. There are various factors that can affect dental caries such as salivary flow, buffering capacity, host immunity. From this study, it can be seen that OHI-S and DMFT do have correlation as increase in the DMFT score leads to poor oral health. Therefore poor oral health as seen in this study increases the risk in general health with compromised chewing and eating abilities affecting nutritional values.

The limitations of this study are the small sample size and geographic limitations. The future scope of this study is to create awareness in effect on dental caries in oral hygiene status among adults.

\section{Conclusion}

In the present study, it can be concluded that dental caries is highly prevalent in adults with poor oral hygiene, majorly among females with a mean value of 7.7 and in the age group 38-40 years.

\section{Acknowledgement}

The authors would like to acknowledge the support rendered by The Department of Public Health Dentistry of Saveetha Dental College and Hospitals and the management for their constant assistance with the research.

\section{References}

[1]. Bagramian RA, Garcia-Godoy F, Volpe AR. The global increase in dental caries. A pending public health crisis. Am J Dent. 2009 Feb;22(1):3-8. PMID: 19281105.

[2]. Omitola OG, Arigbede AO. Prevalence of dental caries among adult patients attending a tertiary dental institution in South-South region of Nigeria. Port Harcourt Medical Journal. 2012;6(1):52-8.

[3]. Lewis DW, Ismail AI. Periodic health examination, 1995 update: 2. Prevention of dental caries. The Canadian Task Force on the Periodic Health Examination. CMAJ. 1995 Mar 15;152(6):836-46. PMID: 7697577.

[4]. Urzua I, Mendoza C, Arteaga O, Rodríguez G, Cabello R, Faleiros S, et al. Dental caries prevalence and tooth loss in chilean adult population: first national dental examination survey. Int J Dent. 2012; 2012: 810170. PMID: 23316234

[5]. Marthaler TM. Changes in dental caries 1953-2003. Caries Res. 2004 MayJun;38(3):173-81. PMID: 15153686.

[6]. Prabakar J, John J, Srisakthi D. Prevalence of dental caries and treatment needs among school going children of Chandigarh. Indian J Dent Res. 2016 Sep-Oct;27(5):547-552. PMID: 27966516.

[7]. Prabhakar AR, Murthy SA, Sugandhan S. Comparative evaluation of the length of resin tags, viscosity and microleakage of pit and fissure sealants - an in vitro scanning electron microscope study. Contemp Clin Dent. 2011 Oct; 2(4): 324-30. PMID: 22346161.

[8]. Prabakar J, John J, Arumugham IM, Kumar RP, Srisakthi D. Comparative Evaluation of Retention, Cariostatic Effect and Discoloration of Conventional and Hydrophilic Sealants - A Single Blinded Randomized Split Mouth Clinical Trial. Contemp Clin Dent. 2018 Sep; 9(Suppl 2): S233-S239. PMID: 30294150.

[9]. Khatri SG, Madan KA, Srinivasan SR, Acharya S. Retention of moisturetolerant fluoride-releasing sealant and amorphous calcium phosphate-containing sealant in 6-9-year-old children: A randomized controlled trial. J Indian Soc Pedod Prev Dent. 2019 Jan-Mar;37(1):92-98. PMID: 30804314.

[10]. Office of the Surgeon General (US). National Call To Action To Promote Oral Health. Rockville (MD): National Institute of Dental and Craniofacial Research (US); 2003. Report No.: 03-5303. PMID: 21028754

[11]. Mathew MG, Samuel SR, Soni AJ, Roopa KB. Evaluation of adhesion of Streptococcus mutans, plaque accumulation on zirconia and stainless steel crowns, and surrounding gingival inflammation in primary molars: randomized controlled trial. Clin Oral Investig. 2020 Sep;24(9):3275-3280. PMID: 31955271.

[12]. Steptoe A, Wardle J, Vinck J, Tuomisto M, Holte A, Wichstrøm L. Personal- ity and attitudinal correlates of healthy and unhealthy lifestyles in young adults. Psychol Health. 1994 Jul;9(5):331-343. PMID: 29022399.

[13]. Gbotolorun OM, Eweka OI, Lawal A, Fadeyibi O, Emeka CI. Knowledge, opinions, and practices about oral cancer among general medical practitioners in Lagos, Nigeria.

[14]. Samuel SR, Acharya S, Rao JC. School Interventions-based Prevention of Early-Childhood Caries among 3-5-year-old children from very low socioeconomic status: Two-year randomized trial. J Public Health Dent. 2020 Jan; 80(1): 51-60. PMID: 31710096.

[15]. Neralla M, Jayabalan J, George R, Rajan J, MP SK, Haque AE, et al. Role of nutrition in rehabilitation of patients following surgery for oral squamous cell carcinoma. International Journal of Research in Pharmaceutical Sciences. 2019 Oct 16;10(4):3197-203.

[16]. Pratha AA, Prabakar J. Comparing the effect of Carbonated and energy drinks on salivary pH-In Vivo Randomized Controlled Trial. Research Journal of Pharmacy and Technology. 2019;12(10):4699-702.

[17]. Gupta DP, Chowdhury R, Sarkar S. Prevalence of dental caries in handicapped children of Calcutta. J Indian Soc Pedod Prev Dent. 1993 Mar;11(1):23-7. PMID: 8040696.

[18]. Solanki J, Gupta S, Chand S. Comparison of dental caries and oral hygiene status among blind school children and normal children, Jodhpur City Rajasthan, India. Univ Res J Dent. 2014 Jan 1;4(1):22.

[19]. Akhionbare O, Ojehanon PI. The effect of dental facilities on the processes of tooth loss between urban and rural populations in Edo State, Nigeria. African Journal of Oral Health. 2018 May 31;7(2):21-8.

[20]. Kumar RP, Vijayalakshmi B. Assessment of fluoride concentration in ground water in Madurai district, Tamil Nadu, India. Research Journal of Pharmacy and Technology. 2017;10(1):309-10.

[21]. Kumar RP, Preethi R. Assessment of Water Quality and Pollution of Porur Chembarambakkam and Puzhal Lake. Research Journal of Pharmacy and Technology. 2017;10(7):2157-9.

[22]. Reddy M, Singh S. The promotion of oral health in health-promoting schools in KwaZulu-Natal Province, South Africa. South African Journal of Child Health. 2017;11(1):16-20

[23]. Hulland S, Sigal MJ. Hospital-based dental care for persons with disabilities: a study of patient selection criteria. Spec Care Dentist. $2000 \mathrm{Jul}-$ Aug;20(4):131-8. PMID: 11203888.

[24]. KANNAN SS, KUMAR VS, RATHINAVELU PK, INDIRAN MA. AWARENESS AND ATTITUDE TOWARDS MASS DISASTER AND ITS MANAGEMENT AMONG HOUSE SURGEONS IN A DENTAL COLLEGE AND HOSPITAL IN CHENNAI, INDIA. WIT Transactions on The Built Environment. 2017 Sep 7;173:121-9.

[25]. Touger-Decker R, van Loveren C. Sugars and dental caries. Am J Clin Nutr. 2003 Oct;78(4):881S-892S. PMID: 14522753.

[26]. Shah N. Gender issues and oral health in elderly Indians. Int Dent J. 2003 Dec;53(6):475-84. PMID: 14725376.

[27]. Delgado-Angulo EK, Bernabé E. Influence of host-related risk indicators on dental caries in permanent dentition. Acta Odontol Latinoam. 2006;19(2):85-92. PMID: 17645216.

[28]. Pellizzer C, Pejda S, Špalj S, Plančak D. Unrealistic Optimism and Demographic Influence on Oral Health-Related Behaviour and Perception in Adolescents in Croatia. Acta Stomatologica Croatica. 2007 Sep 15;41(3):205-15.

[29]. Singh A, Kumar A, Berwal V, Kaur M. Comparative study of oral hygiene status in blind and deaf children of Rajasthan. Adv Med Dent Sci. 2014 Feb;2(1):26-31.

[30]. Jain M, Bharadwaj SP, Kaira LS, Bharadwaj SP, Chopra D, Prabu D, et al. Oral health status and treatment need among institutionalised hearing-impaired and blind children and young adults in Udaipur, India. A comparative study. Oral Health Dent Manag. 2013 Mar;12(1):41-9. PMID: 23474580.

[31]. Pavithra RP, Jayashri P. Influence of Naturally Occurring Phytochemicals on Oral Health. Research Journal of Pharmacy and Technology. 2019;12(8):3979-83.

[32]. Prabakar J, John J, Arumugham IM, Kumar RP, Sakthi DS. Comparing the Effectiveness of Probiotic, Green Tea, and Chlorhexidine- and Fluoride-containing Dentifrices on Oral Microbial Flora: A Double-blind, Randomized Clinical Trial. Contemp Clin Dent. 2018 Oct-Dec;9(4):560-569. PMID: 31772463.

[33]. Mohapatra S, Kumar RP, Arumugham IM, Sakthi D, Jayashri P. Assessment of Microhardness of Enamel Carious Like Lesions After Treatment with Nova Min, Bio Min and Remin Pro Containing Toothpastes: An in Vitro Study. Indian Journal of Public Health Research \& Development. 2019;10(10):375-80.

[34]. Wadgave U, Nagesh L. Nicotine Replacement Therapy: An Overview. Int J Health Sci (Qassim). 2016 Jul;10(3):425-35. PMID: 27610066. 